\section{The war on drugs}

\section{Legalisation may be necessary}

EDIToR,-I agree with Richard Smith that some drugs may have to be legalised. ${ }^{1}$ I remember that, when working at Columbia University, New York, in 1954 I heard Dr Robert Loeb, the head of medicine, deploring the news that the police intended to crack down on illicit drug dealing in Harlem. He had watched prohibition result in alcohol dependence and gangsterism in the United States. When prohibition ended, dependence on alcohol still remained but the gangsterism associated with the drink trade stopped. Loeb predicted that the more the police enforced the law on the illicit drug trade the more profitable the trade would become and the more vicious and rapacious would be the gangsters who would move into Harlem. I think that the experience in the United States since then has more than confirmed his prediction.

The situation in Britain may not yet be as bad as it was in New York in the 1950s, but I believe that we should now be examining ways to eliminate the profit from illicit drug trading; it is the profit that attracts dealers, who play a major part in encouraging young people to use drugs. To eliminate this profit I believe we will have to legalise the use of these "pleasure" drugs, with cannabis to be treated as tobacco is now and hard drugs like morphine, heroin, and cocaine to be available from specified pharmacies. We would still have serious problems of dependence but not, I think, on the huge scale of our current problems with alcohol; but crime would be reduced and the pushers would be eliminated because the enormous profits would no longer exist.

\section{Advice to authors}

We receive more letters than we can publish: we can currently accept only about one third. We prefer short letters that relate to articles published within the past four weeks. Letters received after this deadline stand less chance of acceptance. We also publish some "out of the blue" letters, which usually relate to matters of public policy.

When deciding which letters to publish we favour originality, assertions supported by data or by citation, and a clear prose style. Wit, passion, and personal experience also have their place.

Letters should have fewer than 400 words and no more than five references (including one to the BMJ article to which they relate); references should be in the Vancouver style. We welcome pictures.

Letters should be typed and signed by each author, and each author's current appointment and address should be stated. We encourage you to declare any conflict of interest.

Please enclose a stamped addressed envelope if you would like to know whether your letter has been accepted or rejected.

Letters will be edited and may be shortened.
Other advantages would be that the purity of the drugs could be ensured and that people wishing to purchase hard drugs could be better informed of the dangers and dissuaded more effectively than is the case at present. The disadvantages include, firstly, that the end result would not be perfect: I do not like people taking hard drugs, but the situation would be better than it is at present and much better than it will be if we do nothing. A second disadvantage is that it is difficult for one country in Europe to act alone. The Dutch, who tried to relax implementation of their drug laws, had an influx of drug users from other countries. Britain has some advantages in being an island. A third disadvantage is that there are some drugs such as LSD (lysergide) - and no doubt others yet to be discovered - that are so dangerous that they should remain illegal.

O L WADE

Medical School,

University of Birmingham

Birmingham B15 2TT

1 Smith R. The war on drugs. BMf 1995;311:1655-6. (2330 December.)

\section{Editorial contained specious arguments}

EDITOR, - I find it reprehensible that the editor of the $B M \mathcal{F}$ has decided to support the lobby for the legalisation of drugs. ${ }^{1}$ His specious arguments will be interpreted as the view of the medical profession as a whole precisely because they have come from the editor of the journal.

Prohibition is not "working," but it was never meant to be the measure that would solve society's dependence on drugs, only a way of making it more difficult to become dependent. The trouble with using quotes from writers who know nothing of the incalculable suffering caused by drug misuse is that they may obscure the reasons why people become users in the first place: it is a grave error to assume that people use drugs simply because their life is "monotonous" or "poor." As doctors we should be helping to direct society into finding ways to make its life richer rather than to seek temporary escapism with its added long term misery.

Richard Smith says that legalisation would promote education on how to avoid drugs. Does this mean that we cannot educate people at present? The criminalisation that stems from misuse of drugs will not disappear if we legalise them-it is the misuse itself that causes the criminal acts. Perhaps Smith thinks that the occasional "joint" causes people to turn into muggers, ram raiders, or burglars. Legalisation of tobacco has not resulted in a decline in its use and the resultant long term effects. The fact that seizures of drugs have increased and that a lot of people have experimented with drugs is no evidence that legalisation will improve the health of the nation. The police force has opted not to prosecute people found in possession of small quantities of cannabis, but this cannot be taken as proof that the police and the society they work for approve. It is unclear from the editorial which drugs Smith would seek to legalise: he uses the example of the Netherlands in relation to cannabis, but neither doctors nor the judicial system would claim that misuse of cannabis is a major health or criminal problem. The effects of cannabis on attention and concentration, however, are recognised, ${ }^{2}$ and its consequences in those who drive or operate heavy machinery can be imagined.

Smith fails to deliver a balanced view of the pros and cons of legalising drugs. Such opinions are more fairly expressed in the journal's letters pages or when presented with an opposing argument on an adjacent page.

THOMAS F G ESMONDE

3 Sharman Close,

Stranmillis,

Belfast BT9 5 GF

1 Smith R. The war on drugs. BMf 1995;311:1655-6. (2330 December.)

Grinspoon L, Bakalar JB. Marihuana. In: Lowinson JH, Ruiz P, Millman RB, Langrod JG, eds. Substance abuse: a comprehensiv guide. 2nd ed. Baltimore, MA: Williams and Wilkins, 1992.

\section{An international discussion is desirable}

EDITOR,-Richard Smith states that wars on drugs are doomed to fail and asks whether it is time to consider "going Dutch," referring to the fact that the Netherlands is more willing than other countries to experiment with decriminalisation. What considerations must be taken into account in the debate on the availability of hard drugs in the Netherlands?

Many people argue that hard drugs should be freely available. One argument for this is on grounds of "fairness": why is alcohol freely available and heroin not? But other aspects must also be considered. An argument against prohibition is that it makes international criminal organisations flourish; their activities and economic power are so great that the Dutch government believes that they could constitute a threat to the country's democratic system. ${ }^{2}$ Another argument hinges on the crimes committed against property by a number of drug users and the annoyance and nuisance that users cause in some city areas. Fourthly, prohibition leads to considerable health problems for the users themselves. They spend a lot of time on drug related activities, which results in an unstable pattern of daily activities. Furthermore, there is no possibility of monitoring the quality of the drugs and the devices used. So prohibition has many drawbacks.

Smith wonders whether free availability might be the solution. The expected effects of free availability must, however, be put into perspective. Crimes against property would not be completely abolished because not every user would renounce crime. Another consideration is that a "go it alone" policy could harm international relations. Furthermore, drug tourism would probably increase. Another, less widely discussed problem emerges when comparison with alcohol is made. Increased availability of alcohol may result in higher consumption, which in turn may result in more problems related to alcohol. The same is conceivable for hard drugs: problems related to illegal use would be reduced if drugs were freely available, but other problems-for example, at work or with driving-might increase. So free availability has many drawbacks too.

Partial legalisation would help, but to what extent? Methods of controlled supply to limited groups of users are now being discussed in the Netherlands. More specifically, an experiment is being planned in which heavy users will be prescribed heroin on prescription. ${ }^{23}$ Such experiments are useful, but important questions remain unanswered. For instance, what will the govern- 